Nihon Biseibutsu Sertai Gakkarho

(Bulletin of Japanese Society of Microbial Ecology)

Vol 3, No 2, 67-71, 1989

\title{
Kinetics of Colony Formation by Sulfate-Reducing Bacteria
}

\author{
Manabu Fukui and Susumu Takil \\ Department of Blology, Faculty of Sclence, Tokyo Metropolitan University, \\ Fukazawa 2-1-1, Setagaya-ku, Tokyo 158, Japan
}

\begin{abstract}
The colony formation of sulfate-reducing bacterı, Desulfovibrio desulfuricans and Desulfotomaculum orientis, on agar plates well fitted the theoretical curve of the FOR model proposed by Hattori (1985) The estımates of $\lambda$ for both strains dropped from 5 to 1 day $^{-1}$ with cultivation in a liquid medium or starvation in a buffer solution, while that of $t_{r}$ was not affected so much The estimates of $\lambda$ and $t_{r}$ for $D$. desulfuricans were markedly affected by incubation temperature and lactate concentration in the agar medium Both factors also affected the $t_{r}$ value for $D$ orientis, however only incubation temperature affected the $\lambda$ value for the latter organısm
\end{abstract}

Key words colony formatıon, first order reactıon kinetıcs, sulfate-reducıng bacteria, Desulfovibrio desulfuricans, Desulfotomaculum orientis

\section{Introduction}

Appearance of bacterial colonies on agar plates is considered to follow the first order reaction (FOR) kinetics by Hattori (1985) :

$$
N_{t}=N_{\infty}\left[1-\exp \left\{-\lambda\left(t-t_{r}\right)\right\}\right] \quad\left(t \geqq t_{r}\right)
$$

where $N_{t}$ is the number of colonies at time $t, N_{\infty}$ is the expected number of colonies at the infinite incubation time, $\lambda$ is the rate of the appearance of colonies, and $t_{r}$ is the retardation time. Recently, Fukui and Fukuhara (1987) studied colony forming curves (CFCs) of sulfate-reducing becteria (SRB). Effects of culture conditions and physiological factors on the parameters of the model for SRB have not been clarified yet.

The aim of the present study is to examine the effects of incubation temperature, substrate concentration and culture age or starvation of the inocula on the values of the parameters of the FOR model for SRB Desulfovibrio desulfuricans and Desulfotomaculum orientis.

\section{Materials and Methods}

\section{Organisms and cultivation}

Two strains of SRB, D. desulfuricans (IFO 13692) and D. orientis (ATCC 19365), were used in this study. The growth medium was the $C$ medium of Butlin et al. (1949). The $C$ medium contained $\left(\mathrm{g} \cdot 1^{-1}\right) \mathrm{K}_{2} \mathrm{HPO}_{4}(0.5), \mathrm{NH}_{4} \mathrm{Cl}$ (1), $\mathrm{Na}_{2} \mathrm{SO}_{4}(1), \mathrm{CaCl}_{2} \cdot 2 \mathrm{H}_{2} \mathrm{O}(0.1), \mathrm{MgSO}_{4} \cdot 7 \mathrm{H}_{2} \mathrm{O}(2)$, Na-lactate (3.5), $\mathrm{FeSO}_{4} \cdot 7 \mathrm{H}_{2} \mathrm{O}(0.2)$, and yeast extract (Difco, U.S.A.) (1) ( $\mathrm{pH}, 7.2)$. The autoclaved medium was supplemented with a separately autoclaved reducing agent (sodium thioglycolate, final $0.045 \%$ ).

SRB strains were precultured on the $C$ medium ( $15 \mathrm{ml}$ medium bottles) for 4 days at $30^{\circ} \mathrm{C}$. An aliquot of the culture (ca. $100 \mu 1$ ) was inoculated into the modified $C$ medium filled in $15 \mathrm{ml}$ medium bottles. The medium was modified by reducing the amount of $\mathrm{FeSO}_{4} \cdot 7 \mathrm{H}_{2} \mathrm{O}$ to trace. The bottles were sealed with screw caps and incubated at $30^{\circ} \mathrm{C}$ in the dark. After appropriate incubation times, the cultures were used for the experiments described below. 


\section{Colony count of $S R B$}

Plate counts were obtained by the anaerobic petri dish method of Wakao and Furusaka (1972) using five replicate plates except the experiments described in Figure 1 which were carried out using twenty plates. The medium used was the $C$ medium containing agar $\left(15 \mathrm{~g} \cdot 1^{-1}\right)$, except for the experiment to examine the effect of lactate concentration on colony formation; the lactate concentrations were 3.5 (the original concentration in the $C$ medium), 0.35, 0.035, 0.0035 and $0.00035 \mathrm{~g} \cdot$ $1^{-1}$. The culture was inoculated after appropriate dilution with sterilized distilled water. Numbers of colonies were enumerated by the naked eye at appropriate time intervals during incubation at $30^{\circ} \mathrm{C}$. To examine the effect of incubation temperature on colony formation, plates were incubated at $37,30.525$, and $20^{\circ} \mathrm{C}$.

Parameters of the FOR model, $N_{\infty}, \lambda$ and $t_{r}$, were estimated by the method of Ishikuri et al. (1984).

\section{Starvation of $S R B$}

Cells cultivated for 2 days as described above were harvested by centrifugation at $6000 \mathrm{rpm}$ and $4^{\circ} \mathrm{C}$ for $25 \mathrm{~min}$ and washed twice with anaerobic phosphate buffer $\left(\mathrm{KH}_{2} \mathrm{PO}_{4}, \quad 0.11 \mathrm{~g} \cdot 1^{-1}\right.$; $\mathrm{Na}_{2} \mathrm{HPO}_{4} \cdot 12 \mathrm{H}_{2} \mathrm{O}, 0.64 \mathrm{~g} \cdot 1^{-1} ; \mathrm{pH}, 7.0$ ) while flushing $\mathrm{N}_{2}$ gas. The cell pellets were then resuspended in $10 \mathrm{ml}$ of anaerobic phosphate buffer under $\mathrm{N}_{2}$ gas. A half $\mathrm{ml}$ of these cell suspensions was mixed with $50 \mathrm{ml}$ of the salts solution $(I G)$ of Ingvorsen and J $\phi$ rgensen (1984) in a $120 \mathrm{ml}$ serum vial and starved at $30^{\circ} \mathrm{C}$ under $\mathrm{N}_{2}$ gas. The $I G$ solution contained $\left(\mathrm{g} \cdot 1^{-1}\right)$ $\mathrm{KH}_{2} \mathrm{PO}_{4}(0.11), \mathrm{Na}_{2} \mathrm{HPO}_{4} \cdot 12 \mathrm{H}_{2} \mathrm{O}(0.64), \mathrm{NaCl}$ (1. $0), \mathrm{KCl}(0.5), \mathrm{MgCl}_{2} \cdot 6 \mathrm{H}_{2} \mathrm{O}(0.6), \mathrm{CaCl}_{2} \cdot 2 \mathrm{H}_{2} \mathrm{O}$ (0 2), and $\mathrm{NH}_{4} \mathrm{Cl}(0.25)(\mathrm{pH}, 7.0)$. At appropriate time intervals during starvation, starved cells were inoculated to plates for the plate counts.

\section{Results}

\section{Colony formation by SRB on multiple plates}

Figure 1 shows the changes in the mean number of colonies on twenty parallel plates inoculated with $D$. desulfuricans and $D$. orientis which were obtained from cultures at early stationary phase. Colony formation of both strains well fitted with the theoretical curves of the FOR model. The values of $N_{\infty}, \lambda$ and $t_{r}$ were, respectively, 205, 3.60 day $^{-1}$ and $53.3 \mathrm{hr}$ for D. desulfuricans, and 207, $2.83 \mathrm{day}^{-1}$ and $62.3 \mathrm{hr}$ for D. orientis. The variance, $\chi^{2}$ and significant probability (degree of freedom, 19) of $N_{\infty}$ was, respectively, 204.2, 18.9 and 0.462 for $D$. desulfuricans, and $346.8,31.8$ and 0.630 for $D$. orientis.

\section{Effect of incubation temperature on colony formation}

Incubation temperature affected the parameters for both strains (Table 1). The values of $N_{\infty}$ and $\lambda$ decreased with decreasing temperature in the
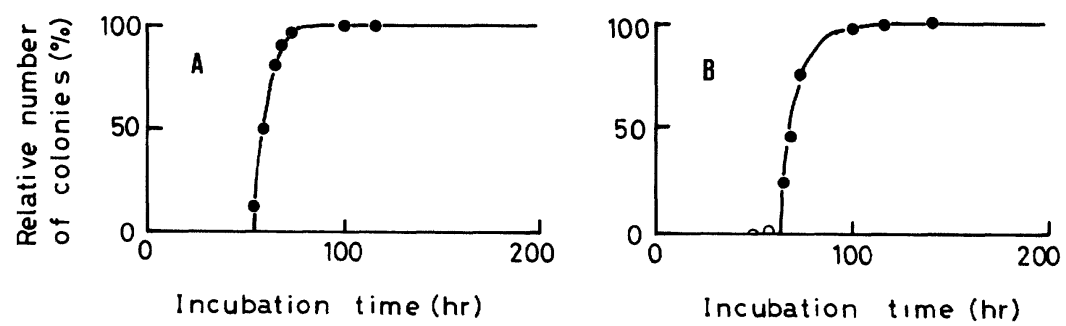

Figure 1 Colony formıng curves of Desulfovibrio desulfurcans (A) and Desulfotomaculum orientis (B) Solıd lines indicate the theoretıcal curves based on the FOR model The estımate of $N_{\infty}$ was arbitrarıly taken as 100 Parameters of each curve are shown in text. Black circles were used for estimation of parameters of the FOR model and white ones were not used 
Table 1. Effect of temperature on values of parameters of the FOR model

\begin{tabular}{c|c|c|c|c}
\hline \multicolumn{1}{c|}{ Strain } & $\begin{array}{c}\text { Temperature } \\
\left({ }^{\circ} \mathrm{C}\right)\end{array}$ & $N_{\infty}$ & $\begin{array}{c}\lambda \\
\left(\text { day }^{-1}\right)\end{array}$ & $\begin{array}{c}t_{r} \\
(\mathrm{hr})\end{array}$ \\
\hline Desulfovibrio desulfuricans & 37 & 255 & 5.21 & 39.9 \\
& 30.5 & 247 & 3.43 & 56.2 \\
& 25 & 227 & 2.28 & 84.7 \\
& 20 & 196 & 1.39 & 130 \\
& & & & \\
& 37 & 398 & 5.79 & 35.6 \\
& 30.5 & 427 & 3.73 & 48.2 \\
& 25 & 399 & 2.94 & 70.1 \\
& 20 & 340 & 1.64 & 118 \\
\hline
\end{tabular}
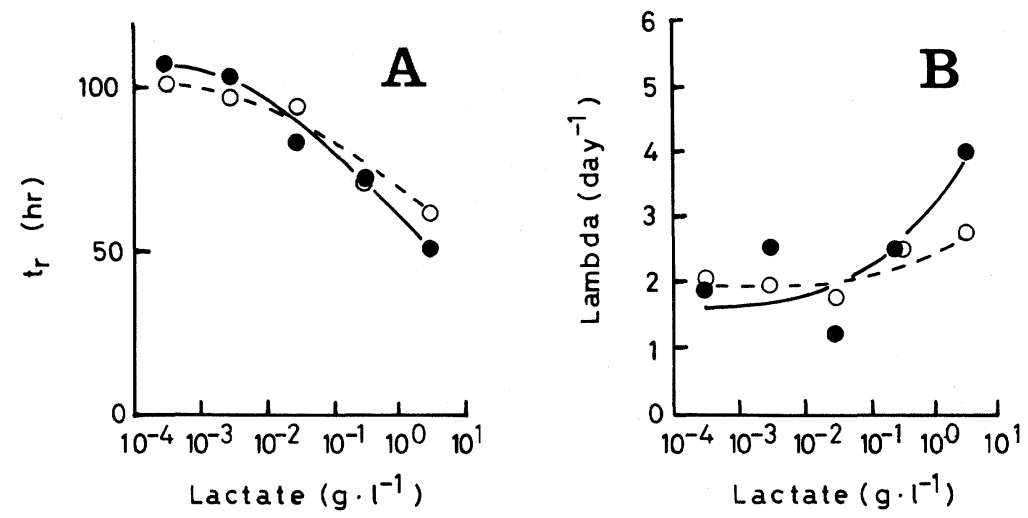

Figure 2. Effects of the concentration of lactate in the medium on the value of $t_{r}(\mathrm{~A})$ and $\lambda(\mathrm{B})$ for Desulfovibrio desulfuricans $(\mathbf{)})$ and Desulfotomaculum orientis $(\bigcirc)$.

range from 37 to $20^{\circ} \mathrm{C}$. Arrhenius relationships were recognized between $\log 1 / t_{r}$ and $1 / \mathrm{T}$, where $\mathrm{T}$ is the absolute temperature. The slopes for both strains were similar.

\section{Effect of lactate concentration on colony formation}

The size of colonies of both strains after fourweek incubation became drastically smaller when the concentration of lactate, a sole source of energy and carbon, decreased from 0.35 to $0.035 \mathrm{~g} \cdot 1^{-1}$, and then gradually decreased with decrease in the lactate concentration. The lactate concentration affected also the value of $t_{r}$ for both strains (Fig. 2A). The value of $t_{r}$ increased with decrease in the lactate concentration and reached to larger than
$100 \mathrm{hr}$ at $0.0035 \mathrm{~g}$ lactate $\cdot 1^{-1}$. The value of $\lambda$ for $D$. desulfuricans dropped as the lactate concentration decreased (Fig. 2-B), while the concentration did not affect the value of $\lambda$ for $D$. orientis.

\section{Effect of culture age on colony formation}

Table 2 shows the effect of culture age of inocula on three parameters for both strains. As the growth phase proceeded from the exponential phase ( 1 to 2 days) to the stationary one ( 3 to 7 days), the value of $\lambda$ for both strains drastically dropped from 5 to 2 day $^{-1}$ and then gradually decreased thereafter. The value of $\lambda$ for $D$. orientis became smaller than 1 day $^{-1}$ after only 19 days, while in the case of $D$. desulfuricans the value became smaller than 1 day $^{-1}$ after 252 days at 
Table 2. Relationship between culture age and parameters of the FOR model

\begin{tabular}{c|c|c|c|c}
\hline Strain & $\begin{array}{c}\text { Culture age } \\
\text { of inocula } \\
\text { (day) }\end{array}$ & $\begin{array}{c}N_{\infty} \\
\left(\mathrm{ml}^{-1}\right)\end{array}$ & $\begin{array}{c}\lambda \\
\left(\mathrm{day}^{-1}\right)\end{array}$ & $\begin{array}{c}t_{r} \\
(\mathrm{hr})\end{array}$ \\
\hline Desulfovibrio desulfuricans & 1 & $3.85 \times 10^{8}$ & 4.25 & 51.7 \\
& 2 & $3.02 \times 10^{8}$ & 4.66 & 55.7 \\
& 3 & $1.10 \times 10^{8}$ & 2.77 & 54.5 \\
& 1 & $1.95 \times 10^{8}$ & 1.77 & 55.7 \\
& 47 & $2.98 \times 10^{5}$ & 2.63 & 53.0 \\
& 99 & $1.88 \times 10^{5}$ & 1.84 & 50.6 \\
& 117 & $2.93 \times 10^{4}$ & 1.61 & 51.4 \\
& 171 & $4.11 \times 10^{5}$ & 1.67 & 54.7 \\
& 252 & $3.10 \times 10^{5}$ & 0.64 & 68.9 \\
& 1 & $8.79 \times 10^{7}$ & 4.60 & 55.4 \\
& 2 & $9.41 \times 10^{7}$ & 5.47 & 58.6 \\
& 4 & $1.26 \times 10^{8}$ & 4.41 & 58.0 \\
& 7 & $7.68 \times 10^{7}$ & 2.24 & 59.1 \\
& 16 & $3.62 \times 10^{4}$ & 1.00 & 76.8 \\
& 19 & $2.03 \times 10^{4}$ & 0.66 & 75.0 \\
& 29 & $1.36 \times 10^{4}$ & 0.57 & 75.5 \\
\hline
\end{tabular}

last. The value of $t_{r}$ was about $50-60 \mathrm{hr}$ before 252 days for $D$. desulfuricans and 16 days for $D$. orientis and then became 10-20 hr longer.

\section{Effect of starvation on colony formation}

The changes in the parameters during starvation are shown in Figure 3. $N_{\infty}$ for both strains showed exponential decreases. The values of $\lambda$ for both strains drastically dropped for only $6 \mathrm{hr}$ of starvation. On the other hand, the values of $t_{r}$ for both strains increased from 55 to $80 \mathrm{hr}$ at $47 \mathrm{hr}$ and then decreased gradually to $60 \mathrm{hr}$.

\section{Discussion}

The CFCs of D. desulfuricans and D. orientis well fitted with the FOR model, like those of Escherichia coli and Agromonas sp. (Hattori, 1985). Thus it is possible to estimate the value of $N_{\infty}$ for both strains by counting $N$ at appropriate time intervals during incubation. Fisher et al. (1922) found that under ideal conditions the num- ber of bacterial colonies from soils on multiplicate plates would vary in the same manner as samples from a Poisson series. Ishikuri and Hattori (1987) also showed that $N_{\infty}$ for Agromonas sp. on multiplicate plates distributed as a Poisson series. The distributions of $N_{\infty}$ on twenty replicate plates for $D$. desulfuricans and D. orientis agreed with their results, as evidenced by the value of significant probability. Therefore, the mean values of $N_{\infty}$ for SRB can be considered as a reliable measure of a viable population density.

The parameter $t_{r}$ is the time lag for colony formation of a population. The value of $t_{r}$ for both strains of SRB became longer with older culture age or longer starvation time (Table 2 and Fig. 3). In the cases of Agromonas sp. and $E$. coli, the generation time was similar irrespective of culture age after the initiation of growth when the cells from various culture age were inoculated, except the lag phase (Mochizuki and Hattori, 1986 ; 1987). Our results suggest that long cultivation in a liquid medium or starvation retarded 


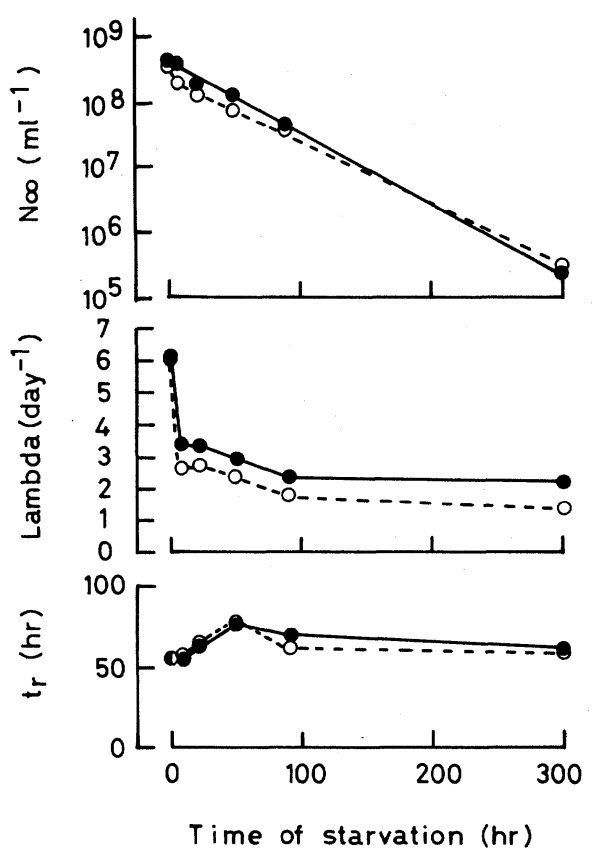

Figure 3. Effects of starvation on the value of the FOR model for Desulfovibrio desulfuricans and Desulfotomaculum orientis $(\bigcirc)$.

growth initiation of original cells of SRB on a plate.

Decrease of lactate concentration resulted in the increase of the value of $t_{r}$, which is partly due to the reduction of their growth rates.

The value of $\lambda$ for $D$. desulfuricans was markedly affected by two factors, temperature and lactate concentration in the medium, but only temperature affected the value of $\lambda$ for $D$. orientis. The value of $\lambda$ for both strains dropped when the cells proceeded from exponential phase to stationary one and for a short period of starvation. In the same experiment of starvation, the ratio of respiring (formazan-forming) but not growing cells to total cells increased with starvation time (Fukui and Takii, 1989). Thus, as supposed by Hattori (1985), the parameter $\lambda$ for SRB may reflect physiological states of original cell populations inoculated to agar plates. To evaluate this relationship, it is necessary to relate the value to biochemical parameters, such as adenylate energy charge.

\section{Acknowledgements}

We are indebted to Dr. S. Ishikuri of the Research Center of Nippon Beet Sugar MFG. Co. for his advice and providing a computer program for statistical calculations.

\section{References}

Butlin, K.R., M.E. Adams, and M. Thomas, 1949. The isolation of sulphate-reducing bacteria. J. Gen. Microbiol., 3, 46-59.

Fisher, R.A., H.G. Thorton and W.A. Mackenzie, 1922. The accuracy of the plating method of estimating the density of bacterial population. Ann. Appl. Biol., 9, 325-359.

Fukui, M. and H. Fukuhara, 1987. Colony formation on agar plates by sulfate-reducing bacteria in water and sediment of lake. Bull. Jpn. Soc. Microbiol. Ecol., 1, 75-78.

Fukui, M. and S. Takii, 1989. Reduction of tetrazolium salts by sulfate-reducing bacteria. FEMS Microbiol. Ecol., 62, 13-20.

Hattori, T., 1985. Kinetics of colony formation of bacteria: an approach to the basis of the plate count method. Rep. Inst. Agr. Res. Tohoku Univ., 34, 1-36.

Ingvorsen, K. and B.B. J $\phi$ rgensen, 1984. Kinetics of sulfate uptake by freshwater and marine species of Desulfovibrio. Arch. Microbiol., 139, 61-66.

Ishikuri, S., Y. Suwa, and T. Hattori, 1984. Method for mathematical analysis of bacterial count data. Soil Sci. Plant Nutr., 30, 249-253.

Ishikuri, S. and T. Hattori, 1987. Analysis of variability of the colonies on parallel plates. Soil Sci. Plant Nutr., 33, 363-372.

Mochizuki, M. and T. Hattori, 1986. Kinetics of microcolony formation of a soil oligotrophic bacterium, Agromonas sp. FEMS Microbiol. Ecol., 38, 51-55.

Mochizuki, M. and T. Hattori. 1987. Kinetic study of growth throughout the lag phase and the exponential phase of Escherichia coli. FEMS Microbiol. Ecol., 45, 291-296.

Wakao, N. and C. Furusaka, 1972. A new agar plate method for the quantitative study of sulfatereducing bacteria in soil. Soil Sci. Plant Nutr., 18, 39-44.

(Received June 21, 1988-Accepted October 14, 1988) 